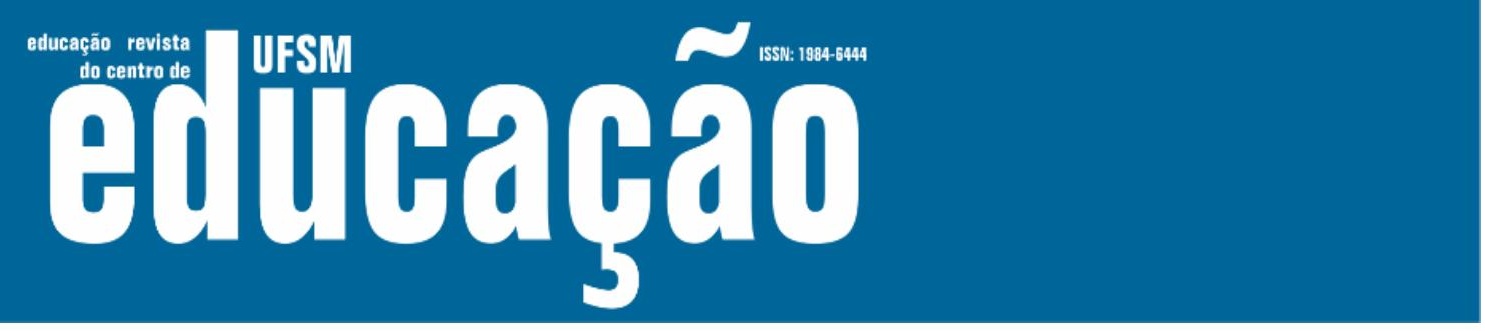

ISSN: 1984-6444 | http://dx.doi.org/10.5902/1984644439376

\title{
Educação Popular e Infância: princípios, concepções e práticas educativas $^{1}$
}

\author{
Popular Education and childhood: principles, conceiving and educational \\ practices
}

Vilma Ribeiro de Almeida

Mestra em Educação. Professora do Instituto Federal de Educação, Ciência e Tecnologia do Pará, Campus Itaituba, Para, Brasil.

vilmaribalmeida@gmail.com - https://orcid.org/0000-0002-1643-7595

Romilson Martins Siqueira

Pós Doutor em Educação Pela UFG. Doutor e Mestre em Educação pela UFG. Professor da Pontifícia Universidade Católica de Goiás - PUC/Goiás.

romilsonmartinsiqueira@hotmail.com - https://orcid.org/0000-0002-6878-9373

Recebido em 03 de agosto de 2019

Aprovado em 11 de setembro de 2020

Publicado em 10 de março de 2021

\section{RESUMO}

O presente texto discute a relação entre Educação Popular e Infância a partir de sua compreensão como práxis social, vivenciada por grupos populares e determinada pela realidade numa perspectiva histórica. Tratou-se de apreendê-las como construtos sociais e históricos que se dão nos planos objetivos e subjetivos. Neste sentido, buscou problematizar temas como direitos, cidadania e participação a partir da experiência do Movimento de Adolescentes e Crianças (MAC). Entre o proclamado e o efetivado, este estudo percorreu fontes legais (Estatutos, Declarações), documentos oficiais do Movimento, bem como escutou os sujeitos (crianças e adultos) envolvidos na experiência. Objetivou, portanto, analisar as concepções, princípios e práticas da educação popular, vivenciadas por crianças e adultos a partir do projeto sócio-políticoeducativo do MAC e investigar como tais valores contribuem para o reconhecimento da criança como sujeito de direitos no contexto da Educação Popular. A análise explicita que o exercício de construção de uma educação crítica, sobretudo de uma educação popular, deve ser permanentemente revisitado. A despeito de o MAC pautar-se nos princípios de uma Educação Popular, tanto esta experiência quanto outras que assim se denominam, precisam reconsiderar o estatuto da infância como condição para o reconhecimento da criança como sujeito com voz e participação. Isto implica revisitar o lugar do adulto na relação com a criança a partir de uma perspectiva dialógica, colaborativa e política numa ruptura com práticas de uma participação decorativa em direção a uma participação protagônica.

Palavras-chave: Educação Popular; Infância e Criança; Movimento de Crianças e Adolescentes (MAC) 


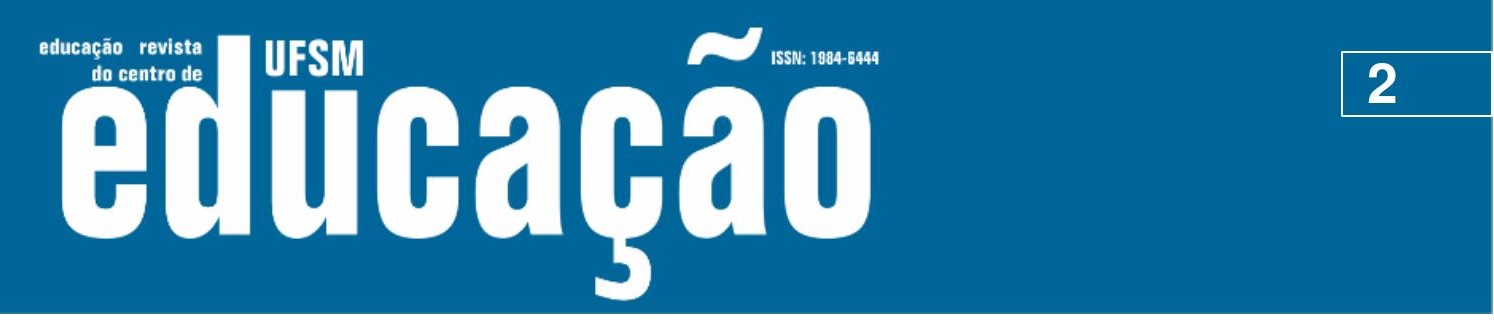

ISSN: 1984-6444 | http://dx.doi.org/10.5902/1984644439376

\section{ABSTRACT}

The present text discusses the relation between Popular Education and childhood, as social praxis, experienced by popular, determined by reality in a historical perspective. It was tried to seize them as social and historical constructs which take place in objective and subjective fields. This sense, it sought to problematize issues such as rights, citizenship and participation from the experience of Teenagers and Children Movement (MAC). Between what is proclaimed and what is made effective, this study covered legal sources (Statutes, Declarations), official documents of the movement, as well as listened to the subjects (children and adults) involved in the experience. The aims was to analyze the conceptions, principles and practices of popular education lived by children and adults from the socio-political-educational project of MAC, and to investigate how these values contribute to the recognition of the child as a subject of rights in the context of Popular Education This work summarizes its analysis by the making explicit that the exercise of construction of a critical education, especially of a popular education, must be permanently revisited. Although MAC is based on the principles of Popular Education, both this experience and others that are similarly called so must reconsider the status of childhood as a condition for the recognition of the child as a subject who has a voice and participation. This implies revisiting the place of the adult in their relationship with the child, from a dialogical, collaborative and political perspective. This presupposes a rupture with practices of a decorative participation towards a protagonist participation.

Keywords: Popular Education; Childhood and Child; Teenagers and Children Movement (MAC).

\section{Introdução}

Uma das maneiras de compreender a relação que se estabelece entre conceitos é situá-los na História, demarcando seus campos de debate e tensão, haja vista que para Lukács, (1981, p. 13) "a história é antes de mais nada, a história dessas formas de sua transformação, enquanto formas de reunião dos homens em sociedade, formas que, a partir das relações econômicas objetivas, dominam todas as relações entre si, [...] relações com eles próprios, com a natureza, etc."

É nesse campo histórico que se encontra a relação entre Educação Popular e Infância. A fertilidade desta relação está na compreensão daquilo que as aproxima: a educação enquanto prática humana e social. Tanto a educação popular (como condição para compreender a cultura, a formação ética e a formação política) quanto 


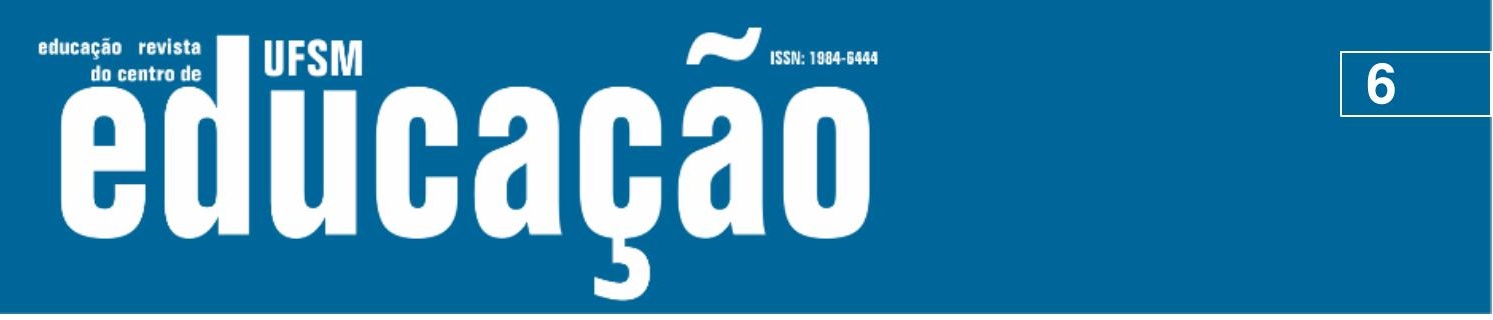

ISSN: 1984-6444 | http://dx.doi.org/10.5902/1984644439376

favor de uma educação mais humanizadora e crítica. Brandão e Assumpção (2009) defendem a Educação Popular como:

\begin{abstract}
uma concepção fundamentada em um referencial teórico-metodológico que parte da vivência e da prática concreta dos sujeitos para desvelar a conjuntura, os aspectos culturais, na perspectiva de recriar o conhecimento e a ação transformadora; exige uma coerência entre a concepção teóricometodológica e o posicionamento político-pedagógico: a intencionalidade de construir a autonomia e emancipação dos sujeitos; os sujeitos populares são reconhecidos como protagonistas do seu aprendizado e de sua emancipação - a aprendizagem é compreendida como processo e não como produto ou resultado; o diálogo e o conflito são constitutivos do processo de aprendizagem, que deve se pautar e construir valores éticos, democráticos e emancipatórios (BRANDÃO; ASSUMPÇÃO, 2009, p. 87).
\end{abstract}

É nessa lógica que se compreende a Educação Popular, cujo papel é importante para a formação e a conscientização da sociedade civil, inclusive na formação, emancipação e politização do sujeito histórico crítico, ao nível individual e coletivo. A Educação Popular é um espaço gerador de culturas e a "história da Educação Popular é reveladora desta diversidade de metáforas e representações sobre o povo que se sucedem e se reforçam em nossa cultura política e até pedagógica" (ARROYO, 2009, p. 402). É um espaço político-pedagógico inesgotavelmente provocador e, consequentemente, dinamizador na construção de novas visões, novos sentimentos, novos comportamentos e, também, novos paradigmas que levam a uma transformação individual e social de relevantes significados, interferindo, sobretudo, na edificação de um modelo de sociedade, em que a cidadania ativa se evidencia.

Segundo Carrillo (2013), a Educação Popular pode ser compreendida a partir de sua concepção pedagógica e como prática social. Ela está altamente sensível "aos contextos políticos, sociais e culturais onde atua [...] incorpora como prática permanente a realização de leituras críticas dos contextos locais, nacionais e continentais [...] tem estado presente ao longo de seu devir histórico" (CARRILLO, 2013, p. 19-20).

Como processo pedagógico e social, a educação popular é humanizadora. Neste sentido, Arroyo (2012) salienta que, a partir do início dos anos de 1960, houve uma proximidade das experiências de educação mais próxima da popular e que este movimento possibilitou a percepção de novos sujeitos. Assim, tem-se uma nova forma 


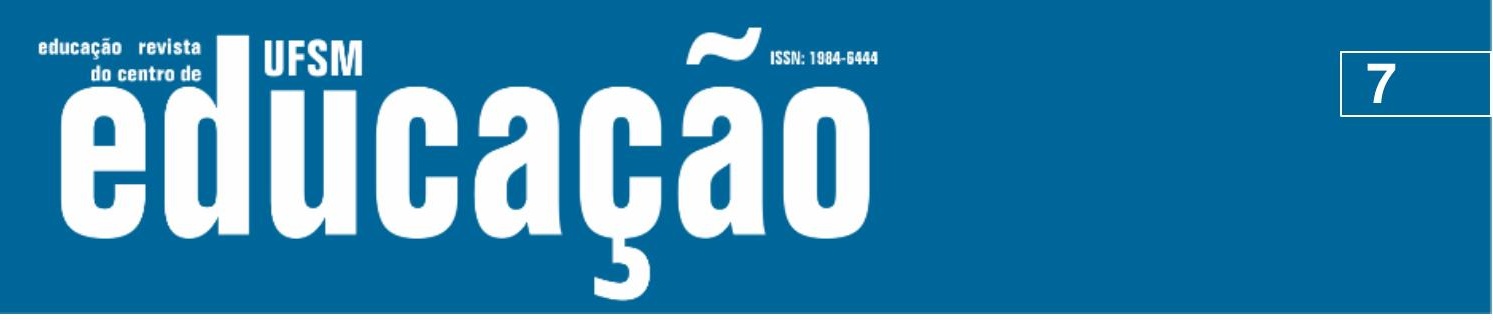

ISSN: 1984-6444 | http://dx.doi.org/10.5902/1984644439376

de compreender a educação "como um processo de humanização de sujeitos coletivos diversos" (ARROYO, 2012, p. 27).

Desse modo, compreende-se que Educação Popular se faz a partir do envolvimento dos sujeitos no processo educacional. Isto posto, o exercício do diálogo constrói as visões de mundo que se manifestam e são questionadas e desmistificadas, podendo, assim, abrir espaço para um novo conhecimento que possibilite uma nova postura frente ao mundo. Não se trata de um diálogo assimilado apenas com a troca de palavras e conceitos, mas de uma relação que se funda na capacidade de ouvir, de questionar, de provocar uma nova prática, não "imposta" ou "repassada", mas construída por essa relação dialógica. Nessa concepção, o diálogo se funda em saber ouvir e falar, por conseguinte, em participação.

\section{O Movimento de Crianças e Adolescentes (MAC): educação popular, direito e participação na infância}

A história do MAC encontra ressonâncias na história da infância brasileira. Entre passado-presente e universalidade-singularidade encontram-se os movimentos de fluxo e refluxo da história em relação a estes temas. Em relação à infância, há que se destacar que qualquer temática que envolva essa discussão não pode apreendêla fora dos espaços de vida social e suas relações de poder. Para isso, faz-se necessário entender que as concepções de infância e de criança não podem ser deslocadas das questões universais que dizem respeito àquilo que expressa o homem e a sua humanidade em processos sociais. Trata de reconhecer a criança em sua condição de sujeito social, uma vez que não existe ser humano isolado de seus contextos sociais, culturais e humanos. Nesse sentido, Touraine (2006) discute essa ideia de sujeito e evoca uma luta social como a de consciência de classe, que induz ao sentido econômico e político que os indivíduos ocupam dentro de uma determinada sociedade, incluídos aí todas as suas reivindicações e interesses.

Da mesma forma, reconhecer a criança e sua infância implica situá-las em sua realidade lógica e histórica, sob condições concretas de vida. Portanto, é necessário apreendê-las na história e como sujeito histórico: "a infância é historicamente 


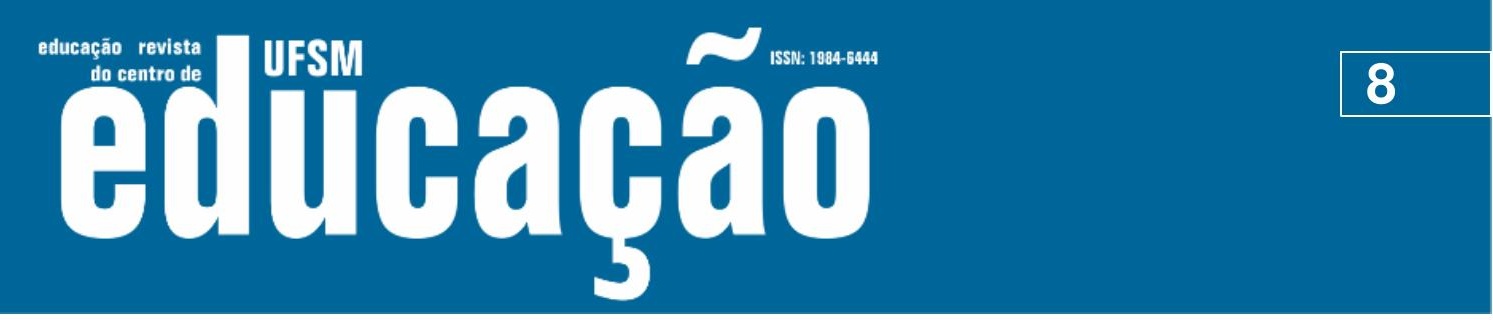

ISSN: 1984-6444 | http://dx.doi.org/10.5902/1984644439376

construída a partir de um processo de longa duração que lhe atribuiu um estatuto e que elaborou as bases ideológicas, normativas e referenciais do seu lugar na sociedade" (SARMENTO, 2005, p. 365).

Para Kramer (2006, p. 13), "a infância é entendida como período da história de cada um, que se estende na nossa sociedade, do nascimento até aproximadamente dez anos de idade." Em Kramer (1999), pode-se encontrar a defesa de um ponto de vista que reconhece o que é específico da infância: o poder de imaginação, fantasia e criação. Contudo, essa autora entende crianças como "cidadãs, pessoas que produzem cultura e são nelas produzidas, que possuem um olhar crítico que vira pelo avesso a ordem das coisas subvertendo essa ordem" (KRAMER, 1999, p. 272).

Para Siqueira (2011, p. 186),

a infância é, de fato, uma construção social que se dá num tempo marcado por singularidades e universalidades no plano natural-social e lógico histórico e a criança é, de fato, um sujeito cujas experiências de vida se dão na articulação entre suas especificidades naturais/biológicas de desenvolvimento e suas condições concretas de existência, social, cultural e historicamente determinada. (Grifos nossos).

Conceber a criança e a infância como construção social implica, portanto, compreender tanto uma quanto a outra em suas condições particulares, singulares e plurais. Isso suscita a constatação de que não existem infância e criança no singular, mas infâncias e crianças no plural, considerando que elas se apresentam em campos histórico-sociais-culturais.

Partindo do pressuposto que a educação não é neutra, entende-se que o diálogo não é instrumento pedagógico, mas princípio de uma Educação Popular. Por se tratar de um processo de humanização dos sujeitos, o diálogo permite apreender o conflito, as contradições e os processos que engendram as relações humanas e sociais. Portanto, ele contribui com transformação individual e social. É neste sentido que a intersecção conceitual entre Educação Popular e Movimento de Adolescentes e Crianças possibilita apreendê-la como práxis social, não institucionalizada, mas que ocorre dentro e com os grupos populares. Nesse sentido, ela é determinada pela realidade vivenciada e de sua perspectiva histórica. Rompe-se aqui com o entendimento da ação educativa como lócus e centrada nos adultos e valoriza-se o 


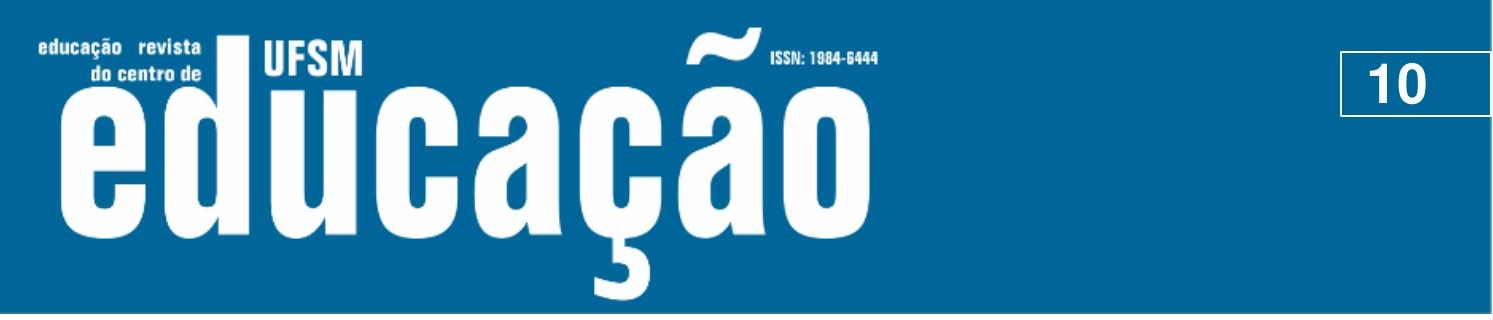

ISSN: 1984-6444 | http://dx.doi.org/10.5902/1984644439376

um tipo de educação que tem como base a dialogicidade, a troca de saberes comunitários e o princípio de que ninguém sabe mais ou menos que ninguém, mas, a ideia que as pessoas sabem outras coisas. Outro aspecto da Educação Popular é que ela não é 'imposta', mas participativa. Além disso, tem por objetivo a transformação da realidade local, ou seja, objetiva transformar realidades de opressão em conquista e garantia de direitos, a partir de reflexões críticas sobre os problemas sociais que afetam a vida de uma determinada comunidade. (Maura)

Nesta perspectiva de Educação Popular, o MAC elaborou em sua proposta educativa os eixos centrais: direito e participação. Estes referem-se, sobretudo, à afirmação das crianças como cidadãs de direitos. Nesse sentido, as discussões que se seguem partem dos estudos dos documentos oficiais do Movimento, das falas ${ }^{6}$ dos sujeitos envolvidos e das observações empíricas ${ }^{7}$ da ação-pedagógica vivenciada neste espaço educativo.

\section{a) Crianças e direitos}

O MAC entende que as crianças são sujeitos portadores de direitos e deveres, capazes de criar, agir, ter consciência do meio em que vivem e criarem condições para transformá-lo, conforme a originalidade própria da idade (MOVIMENTO DE ADOLESCENTES E CRIANÇAS, 2015, p. 9).

Assim, para o MAC, a compreensão de infância perpassa pelo viés do reconhecimento de que cada criança enquanto pessoa inserida em seus tempos e espaços de vida:

quer expressar seus anseios e pontos de vista e ser ouvida e levada em conta... Poder participar da vida em sociedade e fazer sua parte, sendo reconhecida como parceira, tanto quanto os demais parceiros jovens e adultos. Enfim ter voz e vez... Ela não é 'projeto de gente', nem deve ser tratada apenas em função do futuro, como 'esperança do amanhã'. Ela é aqui e agora, uma pessoa humana inteira, com direitos e deveres próprios de sua faixa etária, que quer viver plenamente o hoje da sua existência, como alguém que aprende, certamente, mas também sabe de alguma coisa e tem um conhecimento a comunicar, uma palavra a dizer, uma opinião a dar (MOVIMENTO DE ADOLESCENTES E CRIANÇAS, 2007, p. 31).

Essa discussão inicia-se no Brasil, motivada pelo Movimento de Meninos e Meninas de Rua (MNMMR), juntamente com a Teologia da Libertação e a Pastoral do Menor da Igreja Católica. Estes foram alguns dos movimentos pioneiros na luta pela concepção da criança como sujeito de direitos. Neste aspecto, os movimentos deram 


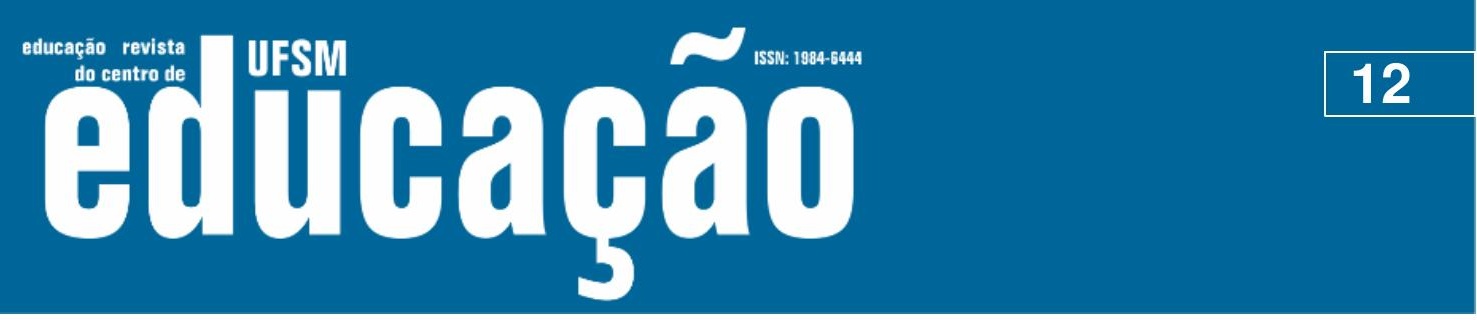

ISSN: 1984-6444 | http://dx.doi.org/10.5902/1984644439376

Direitos de participação - implicam a consideração de uma imagem de infância ativa, distinta da imagem objeto das políticas assistencialistas, à qual estão assegurados direitos civis e políticos, nomeadamente o direito da criança a ser consultada e ouvida, o direito ao acesso à informação, à liberdade de expressão e opinião e o direito a tomar decisões em benefício, direitos que deverão traduzir-se em ações públicas a ela direcionadas que considerem o seu ponto de vista. (FERNANDES, 2009, p. 41-42).

Sarmento e Pinto (1997) corroboram com essa ideia e afirmam que, dentre os três “p", o que menos apresenta progresso mediante a construção política, na organização e na gestão das instituições que trabalham com crianças, é o da participação. Esta é ainda uma fragilidade na garantia e efetivação dos direitos. Entre os três "p", recai a ênfase na Proteção. Esse argumento pode ser explicado a partir da defesa do senso comum de que as crianças precisam de proteção, porque não podem agir com maturidade. Reside nesta ideia a concepção de uma criança frágil, incapaz e incompetente.

Todavia, percebe-se que a discussão em torno do direito da criança vem crescendo ao longo dos tempos. No Brasil, essa questão se evidencia a partir das legislações, principalmente na Constituição Federal de 1988 e no Estatuto da Criança e do Adolescente (ECA) de 1990. Nestes documentos, não há uma menção explícita sobre a criança como sujeito de direitos, porém há o reconhecimento de que ela é portadora de direitos, conforme descrito nos artigos 203, 208 e 227 da Constituição Federal (BRASIL, 1988). Observa-se, aqui, uma crítica importante, particularmente no que se refere à ideia de portabilidade dos direitos. Nesta lógica, o direito deixa de ser algo subjetivo e se constitui como condição para que a criança seja portadora ou não desse direito. Isso aparece de forma mais evidente na Constituição Federal de 1988, que reconhece o direito à vida, à saúde, à alimentação, à educação, ao lazer, à profissionalização, à cultura, à dignidade, ao respeito, à liberdade e à convivência familiar e comunitária como direitos da criança. Estes aspectos evidenciam que a questão da proteção é algo forte na construção da legislação.

De acordo com Siqueira (2011), a legislação brasileira enfatiza a importância do ECA (BRASIL, 1990) como um mecanismo de preservação dos direitos das crianças. Ressalta que o momento social e histórico da criação do ECA significou um marco na história da salvaguarda à criança, bem como uma vitória dos movimentos 


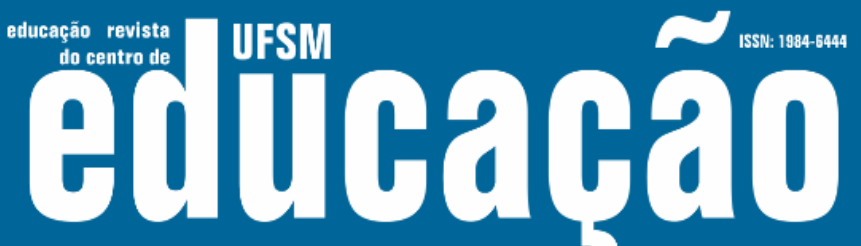

ISSN: 1984-6444 | http://dx.doi.org/10.5902/1984644439376

Ao analisar as falas das crianças nas rodas de conversa ${ }^{10}$ acerca dos direitos, percebe-se que elas demonstram preocupações com os deveres. Estas são marcas de um tempo em que os afazeres estão em evidência:

- Davi: As crianças têm direito de estudar, de cuidar da saúde....

- Karine: Nós crianças temos direitos, mas também temos deveres. Se a gente não cumprir os nossos deveres, não adianta exigir nossos direitos.

- Irene: Temos direito de brincar...

A garantia do direito sempre esteve atrelada à questão do dever, ou seja, sujeito de direitos é similarmente um sujeito de deveres. Estas falas demonstram as preocupações das crianças acerca dos direitos fundamentais, mas, simultaneamente, evidenciam a questão do brincar como um aspecto importante. Assim, o reconhecimento da criança como sujeito com direitos não pode prescindir daquilo que ela traz em relação ao componente lúdico.

Nesta perspectiva, Brougère (2001, p. 52) afirma que a cultura lúdica é também simbólica. Assim, "a brincadeira é, igualmente, imaginação, relatos, histórias". Dando sequência à sua reflexão, Brougère (2001) afirma que a cultura lúdica dispõe de certa autonomia, de ritmo próprio, mas não é isenta, recebe estruturas da sociedade, conferindo-Ihes aspectos específicos. O autor ainda esclarece que ela é igualmente estratificada e não acontece da mesma forma para todas as crianças, já que elas utilizam de maneiras diferentes de brincar. Enfim, a cultura lúdica não está descontextualizada. Ela pertence à cultura geral, à qual a criança pertence.

\section{b) Criança e participação}

Na perspectiva de cidadania política, a questão da participação é uma temática presente na história e não pode ser deslocada do debate político, particularmente daqueles que se organizam e lutam pelo direito de participar. No campo do debate sobre as crianças e suas temporalidades da vida, o tema não se configura diferente. De acordo com Cussiánovich e Márquez (2002, p.12), "o discurso sobre a participação infantil não só exige a desconstrução das representações sociais sobre a infância, mas a construção daquelas que as recuperam como ator social e político". 


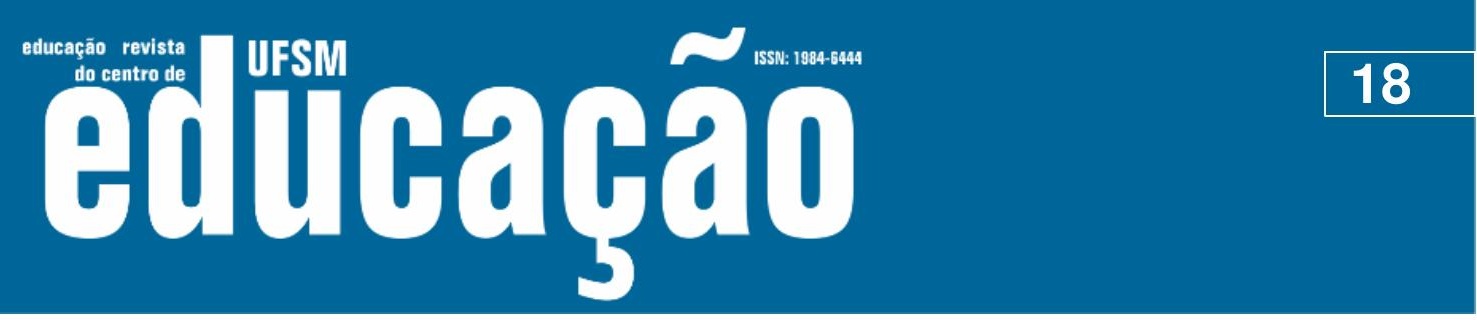

ISSN: 1984-6444 | http://dx.doi.org/10.5902/1984644439376

- Acompanhante: Muito bem. Então vamos cantar pra enviar mais amor para a humanidade.

- Acompanhante: uma palavra tão linda jamais esquecida me fez recordar. Contendo sete letrinhas e todas juntinhas se lê cativar. Cativar é amar é também carregar um pouquinho da dor que alguém tem que levar. Cativou, disse alguém laços fortes criou, responsável tu és pelo que cativou. No deserto tão só, entre homens de bem, vou tentar cativar,viver perto de alguém. Vou tentar tentar cativar viver perto de alguém.

No evento acima, observa-se que as crianças opinam aleatoriamente sobre determinados assuntos. Ainda que o tema tenha relevância e tenha sido recorrente em diferentes encontros, suas opiniões não são tratadas ou aprofundadas pelo adulto que deveria fazer a mediação formativa. Quando as crianças falam de violência, a discussão é interrompida pelo adulto acompanhante com a proposta de cantar para enviar mais amor para a humanidade. Com essa atitude, faz-se um corte na possibilidade da criança expressar as causas da violência ou até mesmo compartilhar sentimentos a respeito deste tema. Observa-se, na postura da acompanhante, a impossibilidade de uma ação concreta que desenvolva a consciência crítica das crianças. Pelo contrário, reforça, em sua atitude, uma posição simplista em que as causas ou problemas sociais são resolvidos com cânticos de amor.

Isso se contrapõe àquilo que Soares (2005b) se refere à participação de crianças. Alerta que, ao promover a participação de crianças, provavelmente a sociedade estaria dando passos na luta contra a desigualdade social e econômica e, com a certeza, na construção de um mundo mais justo e democrático para todos. Da mesma forma, Espinar (2003) ratifica esta posição afirmando que a participação de crianças, enquanto procedimento político ideológico, necessita de um desprendimento dos adultos e das verdades constituídas. Ao mesmo tempo, é preciso construir espaços para que as crianças manifestem suas opiniões e juntos, adultos e crianças, compartilhem de decisões, pois os dois são construtores dos resultados da participação.

Cussiánovich e Márquez (2002, p. 52) afirmam que o direito de opinar rompe com o silêncio social secularmente imposto às crianças e aos adolescentes. Recuperar a opinião e a voz das crianças é recuperar a visibilidade, identidade e dignidade. $\mathrm{O}$ direito de opinar induz ao direito de ser ouvido e escutado e que essa 


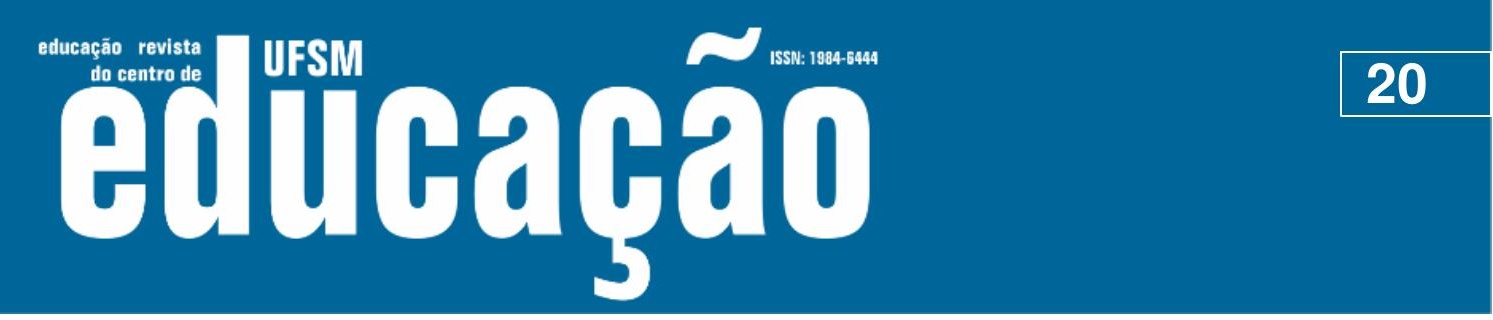

ISSN: 1984-6444 | http://dx.doi.org/10.5902/1984644439376

forma hierarquicamente superior. No entanto, percebe-se a importância política e pedagógica da Educação Popular com crianças, que se faz mediada pela ação dialógica, a qual estimula a curiosidade, possibilita a construção de conhecimento, explicita sonhos, exige criticidade e requer compromisso. Ressalta-se ainda, a importância da ação educativa desenvolvida pelo MAC. Mesmo que de forma incipiente, apresenta-se como um espaço emancipatório de formação cidadã, numa perspectiva de autonomia da criança.

Por fim, reafirma-se a Educação Popular como uma pedagogia e uma posição política: uma pedagogia que a compreenda, ancorada na concepção de mundo com uma metodologia que facilite a participação e o envolvimento das pessoas de forma integral; uma posição política, uma vez que a Educação Popular tem uma proposta clara de transformação e se concretiza na atuação e na organização popular.

\section{Referências}

ALBUQUERQUE, Klaus Paz de. Eu também sou gente: Movimento de Adolescentes e Crianças e Educação Popular. 2009. 144 f. Dissertação (Mestrado em Educação), Faculdade de Educação, Universidade Federal de Goiás, Goiânia, 2009.

ARROYO, Miguel Gonzalez. Outros sujeitos, outras pedagogias. Petrópolis: Vozes, 2012.

ARROYO, Miguel Gonzalez. Educação Popular, saúde, equidade e justiça social. In: Cad. Cedes, Campinas, v. 29, n. 79, p. 401-416, set./dez. 2009.

BEISIEGEL, Celso de Rui. Política e educação popular: a teoria e a prática de Paulo Freire no Brasil. São Paulo: Ática, 1989.

BRANDÃO, Carlos Rodrigues; ASSUMPÇÃO, Raiane. Cultura rebelde: escritos sobre Educação Popular ontem e agora. São Paulo: Editora e Livraria Instituto Paulo Freire, 2009.

BRASIL. Constituição da República Federativa do Brasil. Brasília: Congresso Nacional, 1988.

BRASIL. Câmara dos deputados. Estatuto da criança e do adolescente: Lei 8.069, 13/07/1990, Lei 8.242, 12/10/2001 e Convenção sobre os Direitos da Criança. Brasília: Câmara dos Deputados, Coordenação de Publicações, 1990.

BROUGÈRE, Gilles. Brinquedo e cultura. 4. ed. São Paulo: Cortez, 2001. 


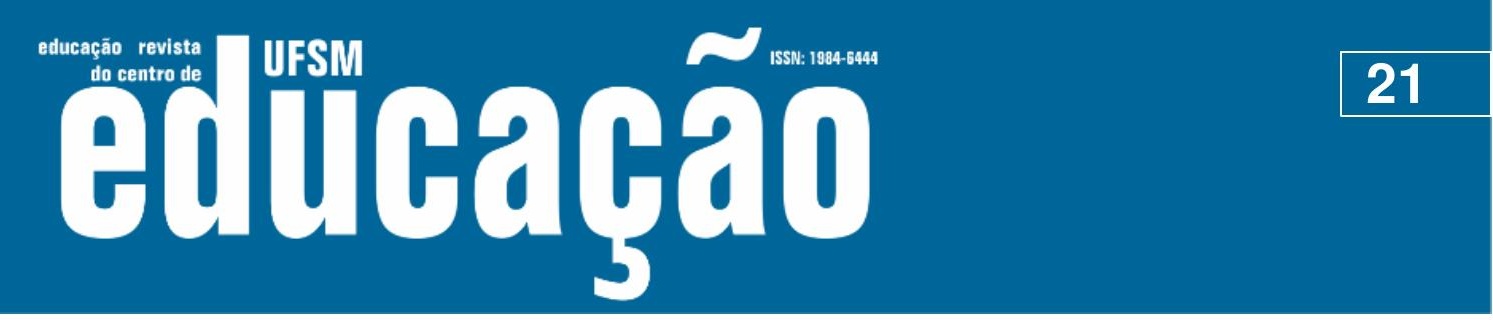

ISSN: 1984-6444 | http://dx.doi.org/10.5902/1984644439376

CARRILLO, Afonso Torres. A Educação popular como prática política e pedagógica emancipatória. In: STRECK, Danilo Romeu; ESTEBAN, Maria Teresa (Org.). Educação popular: lugar de construção social coletiva. Petrópolis: Vozes, 2013.

COUTINHO, Ângela Maria Scalabrin. O estudo das relações Sociais dos bebês na creche: uma abordagem interdisciplinar. Revista eletrônica zero-a-seis, Florianópolis, v. 1, n. 19, jan./jul. 2009. Disponível em: https://periodicos.ufsc.br/index.php/zeroseis/issue/view/1108. Acesso em: 14 jan. 2016.

COUTINHO, Ângela Maria Scalabrin. Ação Social e participação no contexto da creche. Educativa, Goiânia, v. 16, n. 2, p. 217-228, jul./dez. 2013.

CUSSIÁNOVICH, Alejandro; MÁRQUEZ, Ana. Hacia una participación de lós niños, niñas y adolescentes. Documento de discusión elaborado para Save the Children Suécia, 2002.

CHARLOT, Bernard. A mistificação pedagógica: realidades sociais e processos ideológicos na teoria da educação. Tradução Maria José do Amaral Ferreira. ed. rev. e ampliada. São Paulo: Cortez, 2013.

ESPINAR, Angel A. El exercício del poder compartido: Estudio para la elaboracion de indicadores e instrumentos para analizar el componente de participacion de niños y niñas en proyectos sociales. Lima: Escuela para el desarollo e Save the Children Suecia, 2003.

FERNANDES, Natália. Infância, direitos e participação: representação, práticas e poderes. Braga: Afrontamento, 2009.

FREIRE, Paulo; NOGUEIRA, Adriano. Que fazer: teoria e prática em educação popular. Petrópolis: Vozes, 1993.

GAITÁN, Lourdes; LIEBEL, Manfred. Ciudadanía y derechos de participación de lós niños. Madrid: Síntesis, 2012.

KOHAN, Walter Omar. Infância e Filosofia. In: SARMENTO, Manuel Jacinto. GOUVEA, Maria Cristina Soares de (Org.). Estudos da infância: educação e práticas sociais. Petrópolis: Vozes, 2008.

KRAMER. Sônia. A infância e sua singularidade. In: BRASIL. Ministério da Educação. Ensino fundamental de nove anos: orientações para a inclusão da criança de seis de anos de idade. Brasília: FNDE, 2006.

KRAMER Sônia. Infância e educação: O necessário caminho de trabalhar contra a barbárie. In: KRAMER, Sônia; LEITE, Maria Isabel; NUNES, Maria Fernanda; GUIMARÃES, Daniela (Org.). Infância e educação infantil. Campinas: Papirus, 1999.

LIBÂNEO, Luiz Carlos. Pedagogia e Pedagogos: inquietações e buscas. In: Educar em Revista, Curitiba: UFPR, n.17, p. 153 - 176, 2001. 


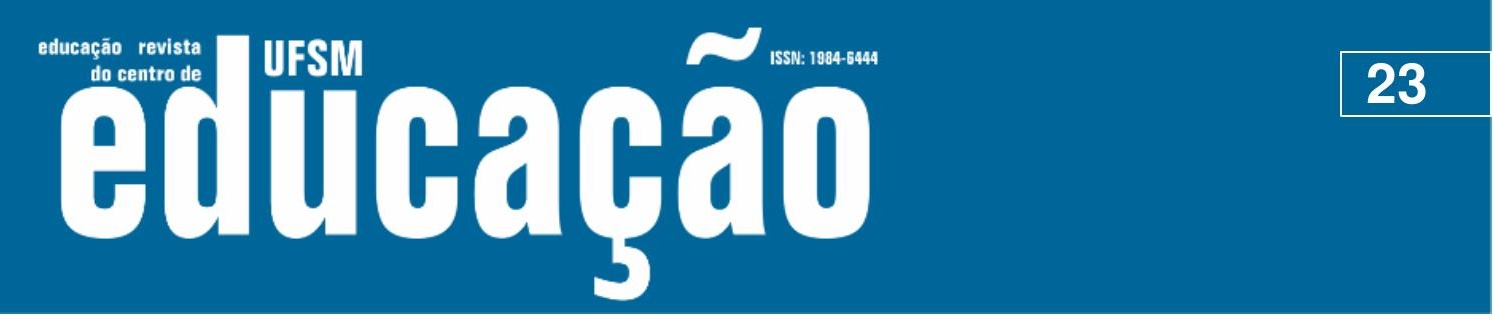

ISSN: 1984-6444 | http://dx.doi.org/10.5902/1984644439376

SOARES, Natália Fernandes; SARMENTO, Manuel Jacinto; TOMAS, Catarina. Investigação da infância e criança como investigadoras: metodologias participativas dos mundos sociais das crianças. Nuances. Presidente Prudente: v. 12, n.13, p. 4963, jan./dez. 2005a.

SOARES, Natália Fernandes. Os Direitos das crianças nas encruzilhadas da proteção e da participação. Revista eletrônica zero-a-seis, Florianópolis, v. 7, n. 12, p. 8-18, jan. 2005b. ISSN 1980-4512. Disponível em: https://periodicos.ufsc.br/index.php/seroseis/article/view/2100. Acesso em: 10 jan. 2016.

SOARES, Natália Fernandes; TOMÁS, Catarina. O Cosmopolitismo infantil: uma causa (sociológica) justa. Revista eletrônica zero-a-seis, Florianópolis, v.11.n.20.jul. /dez.2009.

Disponível

em: https://periodicos.ufsc.br/index.php/zeroseis/issue/view/1207. Acesso em: 14 jan. 2016.

TOMÁS, Catarina. Participação não tem idade: participação das crianças e cidadania da infância. Contextos \& Educação. Instituto de Estudos da Criança da Universidade do Minho Portugal: Editora Unijuí, ano 22 n. 78, jul./dez. de 2007, p. 45-68.

TOURAINE, Alain. Um novo paradigma para compreender o mundo de hoje. Tradução Gentil Tilton. Petrópolis: Vozes, 2006.

UNICEF BRASIL. Convenção sobre os direitos da criança, 1989. Disponível em: www.unicef.pt/docs/pdf_publicacoes/convencao_direitos_crianca2004.pdf. Acesso em: 07 jan. 2016.

This work is licensed under a Creative Commons Attribution-NonCommercial 4.0 International (CC BY-NC 4.0)

\section{Notas}

\footnotetext{
${ }^{1}$ Esse trabalho resulta d estudo de mestrado intitulado: Educação Popular: Movimento de Adolescentes e Crianças (MAC): princípios, concepções e práticas educativas nas vozes das crianças e adultos, defendido em 2016, junto ao Programa de Pós-Graduação em Educação da Pontifícia Universidade Católica de Goiás.
}

${ }^{2}$ De acordo com Beisiegel (1989, p.14), a educação de base era entendida como o processo educativo destinado a proporcionar a cada indivíduo os instrumentos indispensáveis ao domínio da cultura de seu tempo, em técnicas que facilitassem o acesso a essa cultura - como a leitura, a escrita, a aritmética elementar, noções de ciências, vida social, civismo, higiene - segundo suas capacidades, cada homem pudesse desenvolver-se e procurar melhor ajustamento social. 


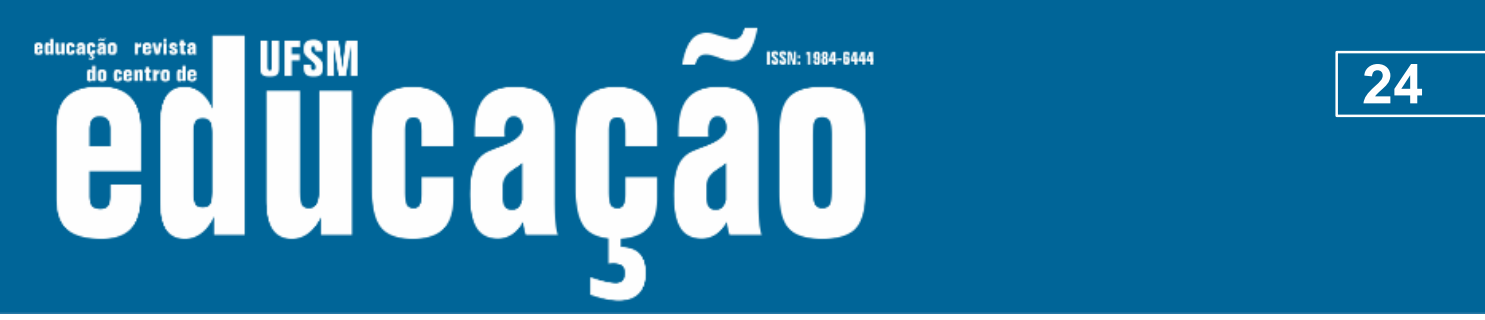

ISSN: 1984-6444 | http://dx.doi.org/10.5902/1984644439376

\begin{abstract}
${ }^{3}$ Para compreender círculo de cultura, é necessário recorrer ao livro Pedagogia do Oprimido de Paulo Freire. De modo geral, o Círculo de Cultura representa conceitualmente um espaço dinâmico, de caráter dialógico de aprendizagem e de troca mútua de conhecimentos, fundamentado na pedagogia libertadora e problematizadora, onde todas as pessoas que o integram participam por meio do diálogo, leem, escrevem, discutem e constroem o mundo em que vivem.
\end{abstract}

\footnotetext{
${ }^{4}$ Maruim também é o nome de um inseto próprio de beira de córregos, rios e mangues.

${ }^{5}$ Acompanhante é o termo utilizado pelo MAC para designar o adulto responsável por conduzir o trabalho formativo com as crianças.

${ }^{6}$ Todo o processo de desenvolvimento deste estudo se deu mediante ao respeito ético necessário para a apreensão de dados.
}

\begin{abstract}
${ }^{7}$ A pesquisa de natureza qualitativa que dá sustentação aos dados aqui apresentados parte dos estudos do tipo estudo de caso, uma vez que apreende em dois grupos específicos do MAC (Goiânia e Cidade de Goiás) os movimentos de sua constituição histórica, suas expressões singulares e suas referências universais com outros grupos com práticas educativas similares. Na pesquisa de campo, de acordo com os critérios preestabelecidos, buscou-se observar as reuniões de dois grupos do MAC. Foram documentados oito encontros (quatro em cada grupo), onde ocorreram as rodas de conversa e os registros fílmicos. Realizaram-se, também, quatro entrevistas, sendo duas com acompanhantes dos grupos e duas com jovens egressos do MAC. Para a coleta de dados, a pesquisadora permaneceu um (1) mês em cada grupo a fim de apreender sua dinâmica interna. Os resultados da pesquisa partiram da triangulação de dados a partir dos diferentes sujeitos (crianças, acompanhantes e egressos), a fim de apreender as categorias analíticas que dão sustentação teórica ao trabalho.
\end{abstract}

8 (UNICEF BRASIL, 1989)

9 “No campo do aparato jurídico-legal, “a institucionalização da “concepção de criança como menor” pode ser apreendida em diferentes documentos que regularam os marcos da criança e da infância brasileira. A infância desvalida apareceu ora em seu discurso protetoral, ora em sua prática coercitiva. Segundo Passeti, (2005 p. 324 e 364), essas ideias se manifestaram: a) no decreto $\mathrm{n}^{\circ} 16.272$, de 20 de dezembro de 1923, que 'regulamenta a proteção aos menores abandonados e delinquentes reconhecendo a situação de pobreza como geradora de crianças abandonadas e de jovens delinquentes;' b) no Código de menores de 1927, que regulamenta o trabalho infantil, c) no Código de Menores a partir do decreto no 17.343/A, de 12 de outubro de 1927, em que o Estado respondeu pela primeira vez com internação, responsabilizando-se pelo abandono e propondo-se aplicar os corretivos para suprimir o comportamento delinquencial; no código de menores de 1979, que atualizou a Política Nacional do Bem-Estar do Menor formalizando a concepção 'biopsicossocial' do abandono e da infração e explicitou a estigmatização das crianças pobres como 'menores'e delinquentes em potencial através da noção de 'situação irregular' expressa no artigo $2^{\circ}$ : para os efeitos deste Código considera-se em situação irregular o menor [...]." (SIQUEIRA, 2011, p. 66).

${ }^{10}$ A roda de conversa foi um procedimento da pesquisa para observar as falas das crianças acerca de alguns temas desenvolvidos pela acompanhante.

${ }^{11}$ Participação decorativa é aquela em que o sujeito participa por meio de consulta, de respostas objetivas a determinadas perguntas, como se fosse um questionário de múltipla escolha em que só uma opção pode ser escolhida. (COUTINHO, 2013, p. 223). 